a maximum stress of $16-17$ tons/sq. in. in sections up to $3 \mathrm{in}$. thick. The use of the new alloy will enable castings to be more effectively designed, as regards the use of thinner sections, and this could result in a saving of weight and, therefore, cost.

\section{New Multi-range Voltmeter}

'TAYLORMETER Model $100 A$ ' is claimed by its manufacturers, Taylor Electrical Instruments, Ltd., to be the first multi-range meter in Great Britain with a sensitivity of $100,000 \mathrm{ohms} / \mathrm{V}$. d.c. The instrument is suitable for voltage measurements in high-resistance circuits, laboratory and research work, and in television and other electronic fields. It can be used in place of a valve voltmeter but without the inconvenience of zero drift, valve replacement and alternating-eurrent supply connexions inherent in valve voltmeters. The d.c. current and voltage ranges are $0.2 \mu \mathrm{mmp}$, to $10 \mathrm{amp}$. and $10 \mathrm{mV}$. to $2,500 \mathrm{~V} .(25,000 \mathrm{~V}$. by means of an external adaptor). The sensitivity on a.c. is $5,000 \mathrm{ohms} / \mathrm{V}$. and the inaccuracies on the d.c., a.c. and ohm ranges are 2, 3 and 5 per cent, respectively. Another now instrument in the Taylor multi-range universal meter series is 'Model 127A', which is a pocket-size meter with a sensitivity of $20,000 \mathrm{ohms} / \mathrm{V}$. d.c. and 1,000 $\mathrm{ohms} / \mathrm{V}$. a.c. It is compact and inexpensive, and utilizes the new rugged Taylor moving-coil centrepole meter and is specially ranged to give maximum reading accuracy for radio and television servicing and maintenance of electrical equipment. A large scale, which is easy to read, with a $3 \frac{1}{4}$ in. arc, is fitted.

\section{Medical Electronics}

A DETAILed and well-indexed bibliography on medical electronics, consisting of 2,200 references, has been prepared by the Medical Electronics Center of the Rockefeller Institute and published by the Professional Group on Medical Electronics, Institute of Radio Engineers, 1 East 79 Street, Now York 21, New York (Bibliography on Medical Electronics. Pp. 91. 2.50 dollars). The term 'medical electronics' has been taken to comprise applications of any of the branches of electronics, such as acoustics, communications, television techniques, spectrophotometry, or dielectric heating, to any problems of biological or medical research, therapy, public health and related fields. The bibliography is intended to serve as source material, and though a selection has been made from all the available material, references useful both to investigators trained primarily in physics or electronies and to those engaged in biology and medicine have been included. The entries are arranged in three sections, the main section consisting of references which are numbered consecutively, listed in numerical order, and grouped together in related topics; a subject index with some crossreferencing; and an author index from which anonymous and editorial matter is excluded although it is included in the previous sections.

\section{A Fossil Meteorite (?)}

What may prove to be a fossil meteorite was discovered at a depth of 32 metres when excavating a mine shaft in the district of Magadan, north-eastern Siberia. As described by A. I. Shulzhenko (Priroda, $5,115 ; 1959)$ it is an iron meteorite weighing about $15 \mathrm{kgm}$., and of a specific gravity of 7.82 , and which on analyses proved to be composed mainly of iron, with 5-6 $\frac{1}{2}$ per cent nickel and $0 \cdot 4-0 \cdot 5$ per cent carbon.
University News :

Birmingham

THE following appointments to lectureships have been made: Dr. M. F. Davies (in botany); Dr. C. R. Sladden (in biology in the Department of Zoology); D. J. Blundell (in geology); K. B. Haley (in engineering production); Dr. N. A. J. Rogers (in chemistry); P. W. Dykes (in medical biochemistry and experimental pathology in the Department of Experimental Pathology).

\section{Glasgow}

THE report of the University of Glasgow Appointments Committee for the year ended December 31, 1958 (Pp. 15. Glasgow: The University. 1959), records a steep rise in the number of men registered, which at 1,051 is almost double the total for 1951 . This is attributed to increasing use of the Committee's services by students, a continuing upward trend in the number of older graduates seeking the advice of the appointments officers, and the increasing number who remain at the University after registering in the final year. Of the total, 735 are in science and engineering, and of these, 302 registered during 1958. Of 574 male students obtaining first or second degrees in 1958, 155 were in science, 122 in engineering and 74 in other technology. Of the total, 333 remained in Scotland. In science, particularly chemistry, there was a proportional increase in the number entering postgraduate research. In spite of the effect of the new defence policy there was no shortage of opportunity except for the less able candidates. Of all honours degree candidates, 122 , or 21.3 per cent, entered the teaching profession compared with $19 \cdot 6$ per cent in 1957 , and in science the proportion rose from $21 \cdot 3$ to $23 \cdot 8$ per cent. There was a further increase in the number of women registered and a slight decrease in the notifications of vacant posts, but the picture is not significantly different from that of 1957, and insufficient opportunity in Scotland for women graduates persists.

\section{Announcements}

To commemorate the late Sir Francis Simon, who was Dr. Lee's professor of experimental philosophy and head of the Clarendon Laboratory, Oxford, the Low Temperature Group of the Physical Society has instituted a Simon Memorial Prize. This is an award to the value of $£ 250$ which is to be made at about three-yearly intervals for distinguished work in experimental or theoretical physics. Dr. Heinz London, of the Atomic Energy Research Establishment, Harwell, is the first recipient of this award.

THE third reactor school course on the Control and Instrumentation of Reactors will take place during February 1-12, 1960, and will be open to British and overseas students. It will be held at Durley Hill, Bournemouth, Hampshire. Further information can be obtained from the Principal, Reactor School, Atomic Energy Research Establishment, Harwell, Dideot, Berkshire. All application forms must be returned by December 11 .

Erratum. In the letter entitled "Colour Centres produced by Radiation in Silica Gel", by Harold W. Kohn, published in Nature of August 22, " $50^{\circ}$ C." in line 12, paragraph 2 , column 1, p. 631 , should read " $500^{\circ} \mathrm{C}$. .". 